\title{
Exploring special need students' perceptions of remote learning using the multimodal model of online education
}

\author{
Lawrence Meda ${ }^{1}$ (I) Zayd Waghid ${ }^{2}$
}

Received: 28 October 2021 / Accepted: 14 February 2022 / Published online: 1 March 2022

(C) The Author(s), under exclusive licence to Springer Science+Business Media, LLC, part of Springer Nature 2022

\begin{abstract}
The global pandemic of COVID-19 forced institutions of higher learning to implement emergency remote learning and to change pedagogical approaches to enhance access and success for all students. Students have mixed views about remote learning. The purpose of this study is to examine special educational needs and disabled students' perspectives of remote learning in the United Arab Emirates. The study was conducted using a qualitative case study within an interpretivist paradigm. Thirty-three special educational needs and disabled students were selected to complete an open-ended questionnaire and participate in semi-structured interviews. It was found that students applauded extraordinary convenience and reasonable accommodation they were getting as a result of remote learning. However, post COVID-19, the majority opted for face-to-face instruction as they described it as 'irreplaceable'. The study concludes that students' nature of special needs and disabilities are influential towards their choice of a mode of instruction.
\end{abstract}

Keywords Special education needs · Online learning - Reasonable accommodation · Remote learning

\section{Introduction}

The current global pandemic, the Coronavirus (COVID-19), has presented university educators with the task of having to develop creative ways to ensure that all students, irrespective of their geographical locations, learning difficulties and disabilities, are provided with access to quality (higher) education. In the United Arab Emirates (UAE), inclusivity continues to receive significant priority and is currently

Lawrence Meda

medalawrence@gmail.com

1 Zayed University, Dubai, United Arab Emirates

2 Cape Peninsula University of Technology, Cape Town, South Africa 
being advocated by policy makers, teachers and university educators more than ever before during the period of the pandemic (Benkohila et al., 2020; Ali, 2021).

The UAE is in full support of inclusion as it ratified the 1994 Salamanca Declaration which advocates for equal opportunities for all students. In this regard, it is expected Special Educational Needs and Disabled (SEND) students are to be included across all levels of education which include primary, secondary and tertiary (Benkohila et al., 2020). The UAE is a signatory to the Convention on the Rights of Persons with Disabilities (CRPD) which requires all students with disabilities to be included in the (higher) education system. In addition, the UAE's Federal Law (29) of 2009 mandates the inclusion of SEND students (Alhammadi, 2017). However, despite the current inclusive frameworks, policies and guidelines mandated in the country, exclusion still occurs in some institutions of higher learning where it was reported that students with disabilities and learning difficulties have lower levels of attendance and were less likely to complete their university degrees within the required time (Benkohila et al., 2020). In this regard, remote teaching and learning we infer is likely to present further significant learning challenges to SEND students in such higher education contexts.

Furthermore, there remains a dearth of empirical research concerning the perspectives of SEND students regarding emergency remote learning (ERL) in the UAE. Several recent studies have been conducted with students who do not have special needs regarding their experiences of remote learning since the start of the global pandemic. These include in-service teachers' perceptions concerning how their students cope during emergency remote instruction (Jelinska \& Paradowski, 2021); pre-service teachers' perspectives of student evaluations using online and face-to-face learning (Bergman, 2020); pre-service teachers'experiences of current practices in cultivating a community of inquiry through remote teaching and learning in South Africa (Waghid et al., 2021) and in Kenya (Chiroma et al., 2021) and pre-service teachers' experiences of remote learning in an early childhood practicum (Kim, 2020). Jia and Santi (2021, p. 1186) argue that "we need to consider students with disabilities' perspectives" in this current period of remote learning. A lack of knowledge in this area is what this study seeks to address.

It is against this background that this study aims to examine SEND students' perspectives of remote learning in the UAE. The paper begins by presenting this current section as the introduction to the study. This is followed by a review of literature which focused on accommodating SEND students. Picciano's (2017) Multimodal Model for Online Education has been used as the theoretical framework for the study. Methods, results and discussion are presented thereafter. The paper ends with a succinct conclusion and implications for further studies.

\section{Literature review}

There is a need for providing extra support to SEND students during this time of COVID-19. These students need their accommodations met as a criterion to optimise their learning abilities in higher education. Sandoval et al. (2021) argue that universities are challenged to be proactive in making continuous reasonable 
adjustments in order to cater for the constantly changing needs of SEND students during the time of ERL. Zabeli et al. (2021) concur that there is a need for institutions of higher learning to develop internal institutional mechanisms to ensure that needs of all SEND students are accommodated. This is because reasonable accommodation is one of the pillars upon which the recognition of the rights of people with disabilities rests (De Asis, 2016).

Faculty members play an important role in making sure all students, including SEND, are getting the differentiated support they need, otherwise they will not be successful. A faculty member at a university in Spain provided reasonable accommodation to SEND students in class by giving them different types of assessments (oral and written) in accordance with their special needs (Sandoval et al., 2021). Although few SEND higher education students in Kosovo had concerns about inclusion, the majority were satisfied with reasonable accommodations they were getting from their professors (Zabeli et al., 2021).

Provision of reasonable accommodation is sometimes interpreted differently by academics. Some say it is unfair as it gives preferential treatment to SEND students and is a disadvantage to students who do not have disabilities (Vasek, 2005). Some interpret it as something that lowers academic standards since content and assessments may be adjusted (Cook et al., 2009). However, if SEND students' accommodations are not met, they cannot participate in the learning process like students who do not have any disability. Thus, reasonable accommodation has to be made to level the playing field so that all students (regardless of their learning difficulties and disabilities) are placed in the correct position which will allow them to maximise their learning experiences. Zhang et al. (2010) contend that reasonable accommodations are critical to the success of students with disabilities. Lopez-Gavira et al. (2021, p. 1) echoed the same sentiment that reasonable adjustments are a 'fundamental requirement to handle the different needs of students with disabilities.' They enable SEND students to participate and produce the desired results (Schreuer \& Sachs, 2014).

If SEND students' learning needs are not met during ERL, they are likely to dislike online learning in general. A study conducted in Malaysia found that university students had a high level of acceptance of online learning after COVID-19 (Sim et al., 2021). These results may not be a true reflection of SEND students' preferences unless they get differentiated support during ERL. Faculty members need to have a positive attitude towards supporting SEND students online. If faculty members have negative attitudes towards the inclusion of SEND students, they (faculty members) will not provide reasonable accommodations which makes it hard for students to achieve their full learning potential.

ERL can be accessed by SEND students provided their needs are taken into consideration. To some SEND students, remote learning is more convenient compared to face-to-face instruction. Barden (2017) argues that remote learning is good for disabled students as it comes with flexibility and convenience such as setting up their home study area according to their individual preferences which will make it easy for them to progress. Students will be able to sit, read aloud and adjust lighting to their convenience when they study from home. They may not be able to do those things in a class with other students who do not have disabilities. Dikusar (2018) 
states that SEND students find ERL convenient as they can study in a way and at a speed which is convenient to them which leads to a more personalised learning atmosphere. Besides the convenience, it is argued that generally, disabled students find ERL more fulfilling and less difficult (Barden, 2017). Courses taught online usually apply multiple teaching strategies and that is at the cornerstone of the universal design for learning which is a framework recommended for SEND students as it gives them equal opportunities to succeed.

It is important to note that not all SEND students find remote learning suitable and convenient. Some find it hard and they struggle to cope with it. More than 50\% of SEND Irish higher education students reported that they were struggling to cope with ERL either because of distractions they had at home or the nature of their disability made it hard for them to learn online (Ahead, 2020). It is possible that students with a similar disability may have different preferences when it comes to online learning or face-to-face instruction (Sim et al., 2021). This is why many students prefer a blended learning approach.

\section{Theoretical framework}

The Multimodal Model for Online Education is adapted as a theoretical framework for this study. The original model comprises six fundamental pedagogical goals and subsequent approaches for achieving them to formulate learning modules (Picciano, 2017). These include content, social/emotional, dialectics/questioning, reflection, collaborative learning and evaluation. The six components form an integrated community of learning in which rich interaction, whether online or face-to-face, can be provided and blended across all modules (Picciano, 2017). However, not all six components of the model may be integrated into individual courses. Instead, the pedagogical objectives of each course should drive the activities and hence the approaches needed for effective learning (Picciano, 2017). The six components are discussed further below.

\subsection{Content}

Content is an essential driving element of the model concerning instruction that transcends from the simple teacher-centred to a more progressive student-centred approach (Picciano, 2017). The model suggests multiple technologies, including gamification and traditional Course/Learning Management Systems (C/LMS), are means by which course content can be delivered by lecturers efficaciously to students through a multitude of media including audio, video and text (Picciano, 2017).

\subsection{Social or emotional element}

The social or emotional element acknowledges the need for lecturers or tutors to engage with students through support by assisting them with understanding complex terminology, offering career advice and through subsequent professional 
opportunities (Picciano, 2017). Through this pedagogical approach, the physical presence of a lecturer or tutor, in addition to providing instruction, is deemed comforting and familiar to students (Picciano, 2017).

\subsection{Dialectics or questioning}

Dialectics or questioning is a vital pedagogical approach that enables university lecturers to ascertain students' knowledge and subsequently assist them in refining their knowledge (Picciano, 2017). One strategy to enable students to think critically about a topic or issue is by using discussion forums that are usually integrated in C/LMS (Picciano, 2017). A discussion forum aims to present a topic to students, thereby requiring them to provide their insight while responding and evaluating these responses (Picciano, 2017).

\subsection{Reflection}

Reflection can be integrated into teaching and learning as a powerful approach in which students can be afforded spaces to share their thoughts with others, which can be a profoundly personal, beneficial and enriching social activity for them (Picciano, 2017). Blogs and reflection journals are apposite tools affording groups or individual students the means to reflect what they learn, which is useful in assisting their lecturers to see how they learn in an online space (Picciano, 2017).

\subsection{Collaboration}

Collaboration is a practical pedagogical approach for group problem solving (Picciano, 2017). While collaboration was sometimes challenging in face-to-face classes, using mobile technology, email and other forms of electronic communication mitigates some of the logistical problems (Picciano, 2017). Wikis have grown in popularity over the last decade and are a vital tool for co-constructing new knowledge and creating opportunities for evaluation and peer review (Fredericksen, 2015; Picciano, 2017).

\subsection{Evaluation}

Evaluation is considered by Picciano (2017) as the most crucial component of the model. Current online assessment methods, including tests, assignments, papers and portfolios, enable lecturers to assess students and provide feedback and serve as a permanent and accessible academic record (Picciano, 2017). Other online tools such as YouTube videos and podcasts, including electronic multimedia, namely images and audio, enable students to present their work without being confined to a classroom in terms of time and space (Picciano, 2017).

Picciano (2017) added three additional components to the original model: community, interaction and self-paced independent instruction (See Fig. 1). Drawing on original studies of Garrison et al. (2000), the course is conceived of as a learning 


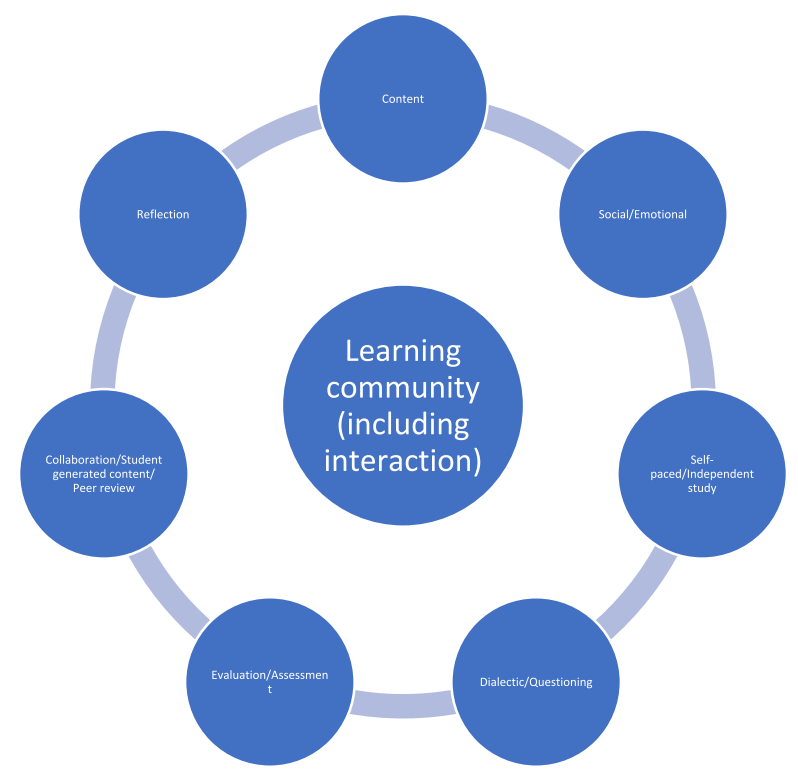

Fig. 1 Multimodal Model for Online Education, adapted from Picciano (2017)

community and can be extended to a more extensive academic programme. Interaction is a fundamental characteristic of the learning community and permeates the model to the extent needed (Picciano, 2017). The most significant revision to the original model is the self-study/independent learning module. In the Multimodal Model for Online Education, self-study/independent learning can be integrated with the other modules as required or as the primary mode of instructional delivery (Picciano, 2017).

\section{Methods}

The study was conducted using a qualitative case study within an interpretive paradigm. A qualitative approach was chosen as it enabled participants to freely express their perspectives about ERL. It also enabled the researchers in this study to interact with participants extensively to understand the phenomenon. Creswell and Poth (2018) argue that a qualitative approach is ideal to use in a study that seeks to collect textual data as it enables them to share their perspectives and experiences. An interpretivist paradigm was selected because of its compatibility with a qualitative approach. The two approaches (qualitative and interpretive) complement each other in a research study. Lapan et al. (2012) concur that the two complement each other as all qualitative research has an interpretive perspective that focuses on uncovering participants' perspectives about a subject under investigation. The study was done as a case study of a federal university in the UAE. A case study was chosen as it enabled researchers to conduct an in-depth investigation about SEND students' perspectives about ERL. Yin 
(2018) postulates that case studies are suitable for studies that seek to make a thorough investigation about a particular phenomenon within a specific setting.

Purposive sampling, which is characterised by deliberate targeting of information-rich participants (Cohen et al., 2017), was used to select students who are registered by the university as SEND. The UAE identifies these students as people of determination, however, in this study they are referred to as SEND students as that terminology is recognised internationally. All 150 SEND students $(n=150)$ were invited to participate in the study by one of the researchers who is based at the institution where the data was collected. Only $33(n=33)$ agreed to share their perspectives about ERL.

Data was collected using an open-ended questionnaire completed by all 33 SEND students $(n=33)$ who agreed to participate in the study. Of the 33 students $(n=33)$ who completed the questionnaire, 10 students $(n=10)$ were requested to participate in one-on-one semi-structured interviews (see Appendix). A questionnaire enabled participants to express their views about the phenomenon while interviews were used by the researchers to ask probing questions to enable students to elaborate on issues they raised. Creswell (2012) argues that open-ended questionnaires and semi-structured interviews are ideal for using in research that requires participants to share and elaborate on their views. Data was analysed using content analysis where the researchers first and foremost read through all textual data; they organised it and created numerous codes which were later collapsed into three main themes - extraordinary convenience, reasonable accommodation and post-COVID-19 preferences. Each of these themes was discussed in depth in the results section. Data analysis was done in line with the Multimodal Model for Online Education as it is the theoretical framework guiding the study.

As part of ethical consideration, an ethical clearance certificate was sought from the university's ethics committee. The purpose of the study was explained to all participants. Participation was voluntary and each participant was free to withdraw from the study at any point in time. Consent forms were signed prior to participation in the study. Confidentiality was maintained throughout the study and pseudonyms were used.

\section{Results}

In this study, results are presented according to the three main themes that emerged from the findings. All the three themes were equally important as they were reiterated by participants. The themes are extraordinary convenience, reasonable accommodation and post-COVID-19 preferences.

\section{Extraordinary convenience}

The ordinary online learning convenience which is often reiterated by students, especially those who have no special needs, is that they can study from anywhere and at any time. This is different from the convenience which was reported by 
students who participated in this study where they mentioned extraordinary convenience which corresponds with their special needs. Students mentioned that online learning was convenient to them as it enabled them to sit in comfortable positions which they could not do in face-to-face classes. One participant said: "Online learning is very convenient for me because I can continuously change my sitting position during class. I cannot do that in a face-to-face class." Another participant supported this view saying: "I can sit in any position I like."

Students with visual impairment reiterated that online learning was good as it allowed them to adjust room lighting to their convenience. A participant said:

You know, as a special needs student with low vision, sometimes I need to sit in a dark place. I can do that in online learning; I can sit alone in a place where I can read out loud and adjust brightness of light in the room by closing or opening curtains. I cannot do that on campus.

Another participant echoed the same sentiments about convenience of lighting in online learning:

The Student Accessibility Services (SAS) centre sometimes helped me by switching off lights in the room when I was on campus, but that was only happening when there were no other students in the room. If there were other students, lights were kept on.

Students with low vision who required brightness in the rooms to be altered could only experience lighting convenience on campus when they were in class without students who did not have special needs. It was very easy for visually impaired students to adjust lights to their convenience during online classes as they could make their rooms at home dark or bright as they pleased. A participant commented about the importance of lighting saying: "brightness of the room is very important. Sometimes the light of the sun reflects on the screen of the magnifier which causes a lot of stress."

Special needs students reported the convenience of ERL as it enabled them to read aloud in order to improve their comprehension skills. A participant supported this saying:

When I joined the university during the time when we were studying on campus, it was a bit hard because they started to let me practise using magnifiers. It was stressful for my eyes because I used magnifiers for long in order to read my exams. But, with online learning where I will be studying from the house, I can read the question out loud to myself. That helps me understand better and I can use the voice over on Zoom, and on Blackboard, I can zoom and read and read the question loudly. So, it is much better to study online for me than face-to-face.

Similarly, another participant supported the convenience of reading aloud saying:

When I read, I cannot read loudly on campus because there are other students in class. So, I have to respect the others in the exam by not reading 
aloud as that will interrupt them. But, with online learning, I can read out loud and understand the content better.

Another participant said: "I can read loudly and understand better than when I do not read aloud. If I read loudly, it is like someone is reading out for me." Students reported that it was easier and more convenient to meet their lecturers for consultations online than it was during face-to-face learning. A participant supported this saying:

With online learning, it is easy and faster to reach lecturers in their office hours as compared to face-to-face learning on campus. On campus, sometimes the schedule is not suitable for us to visit lecturers in their stated office hours. Sometimes we have to leave another class in order to attend one lecturer's office hours. But, with online learning, it is just an email or some of the lecturers are ok with contacting them by WhatsApp. So, just by sending a message we can do a Zoom meeting and it is much easier and convenient.

All students with low vision praised ERL because it enabled them to have quality recordings of classes which they could review as many times as they wanted and at times convenient to them. A participant said: "I like it [ERL] because it has recordings which I can listen to as many times I want." Similarly, another participant said: "as a low vision student, I depend on listening so much. Through online learning, I can understand better and the lessons and lectures are recorded. I can go through the class recording as many times as I want." Special needs students liked the quality of recordings done online compared to those done in face-to-face classes. A participant supported this saying:

In a normal face-to-face class, I used to record the lectures, but sound quality was not very good. It is different now because the sound of the instructor is very clear in online classes. I can hear very well not like the normal class which I used to record using my iPhone where it was not clear as the sound was very far. It is not clear like online.

Another participant concurred with this saying: "the big benefit I got from learning online is the video. It is good quality, and I can play it every now and then until I understand what the professor is teaching." ERL was convenient to the students as it made it easier for their accommodations to be met.

\section{Reasonable accommodations}

Special needs students reiterated that faculty members were providing reasonable accommodations which enabled them to fully participate in online learning. A participant said:

The disability centre at the university tries to make the accommodations for me. I talk to a faculty member on WhatsApp about things that I need to be supported with in her class and she tries to help me in everything that I needed. 
Another participant concurs that her accommodations are being met: "Professors who teach me provide material in a format which is accessible to me as a low vision student." Similarly, another participant said:

As a registered student of determination, professors give me enough extra time. Extra time given may not be enough for me if it is face-to-face because I will be using magnifiers which strain my eyes. But, when that extra time is given online, it is okay because I can read the question aloud to understand and I can zoom in and out in order to see easily.

In some instances, participants reiterated that faculty members modified assessments as part of accommodating the specific needs of some students. This was confirmed by a participant who said:

They change the assessment to accommodate my needs. They can give me like a report to write or an assignment and another assessment because from the screen reader, some things did not work, for example completing multiple choice questions. For my case I do not use respondus lockdown browser because some functions are not compatible with my screen reader.

It is hard for a student with low vision to use Blackboard's respondus lockdown browser. When a student zooms in and out and tries to get closer to the screen to see clearly, that movement will be detected by a camera and recognised as cheating which results in getting a warning from the system. To accommodate such students, faculty members did not require students with low vision to use respondus lockdown.

Students were very appreciative of the nature of support they received while using ERL. One participant said:

Faculty professors and SAS staff are very supportive and helpful. I really appreciate what the university is doing to support us with online learning. I am so happy with the support I am getting as a student with low vision and majoring in environment and sustainability. This major has a lot of Chemistry, Physics and Labs. In the Labs they are helping me, everything is going very well.

Another participant said: "SAS provide all the support for us, to be honest they have everything. For example, if you need more help, they provide someone who can give you sort of a tutorial to assist you." This issue of supporting all registered special needs students was confirmed by two participants who said:

SAS appointed someone to help me. The person supports me every day for 10 - 20 minutes. But, even though she tries I cannot learn fully. SAS tries to support me to be honest. But still, it is better for me to learn on campus using face-to-face than online.

I have adequate support from SAS. When I finish my work I go and show them. Someone looks at my work and helps me correct grammar and spelling mistakes. There is someone at SAS who offers me learning support, when I finish my assignment, I go to ask her to check grammar and everything. 
Both faculty members and SAS staff were very instrumental in enhancing special needs students' learning experiences. A student confirms this saying:

Yes, they were really supportive to be honest. For example, in one of the courses that I used to take last semester, I had to do a project and I did not know how to do it. I asked the professor how to do it. She was very helpful. She explained many times until I understood.

Despite all the praise given by many students about how much they liked online learning, few students felt that support offered could have been better. One participant felt that some faculty members were very supportive, but others were not. The student said: "Most of my professors have been very supportive and were always willing to help, but some of them were a little inconsiderate and did not seem to care that much." Another student was negative about her accommodations being met. She said: "no, they do not even follow accommodations and during meetings they would promise to change Powerpoints to be more efficient and upload them earlier, but they do not do whatever they say they would do." The fact that some students felt their accommodations were not fully met online led to them having a preference of reverting to face-to-face learning when the COVID19 pandemic is over.

\section{Post-COVID-19 preferences}

When students were asked which mode of learning they would prefer when COVID19 lessens or is over, the total number of students who preferred face-to-face classes outweighed the number of students who opted for online and blended learning modalities. This is illustrated in Fig. 2.

A total of 21 students $(63.6 \%)$ preferred face-to-face learning on campus. The selection of this learning mode was mainly influenced by the nature of students' learning disability which restricted them from optimising ERL. A participant said:

I am a person who prefers physical face-to-face learning where I can see the professor. It is more comfortable for me than online learning which I find hard to concentrate. When I sit in front of the laptop for more than 55 minutes, my eyes shed tears. An eye specialist said I should not spend more than 50 minutes on a device because of my eyes and my age which is now 56 . When I work on a laptop for a long time, I see the words, or sentences like moving.

A student who suffered from migraines and dyslexia preferred face-to-face learning because of her condition. She said:

Since both migraines and dyslexia have an affect on my vision, they make it very difficult for me to see well when I am working online. I am constantly dizzy during classes and exams. I even fainted during one of my midterms. I would like face-to-face learning because of my condition which makes it hard for me to learn online. 
Which learning option would you prefer after COVID-19:

33 responses

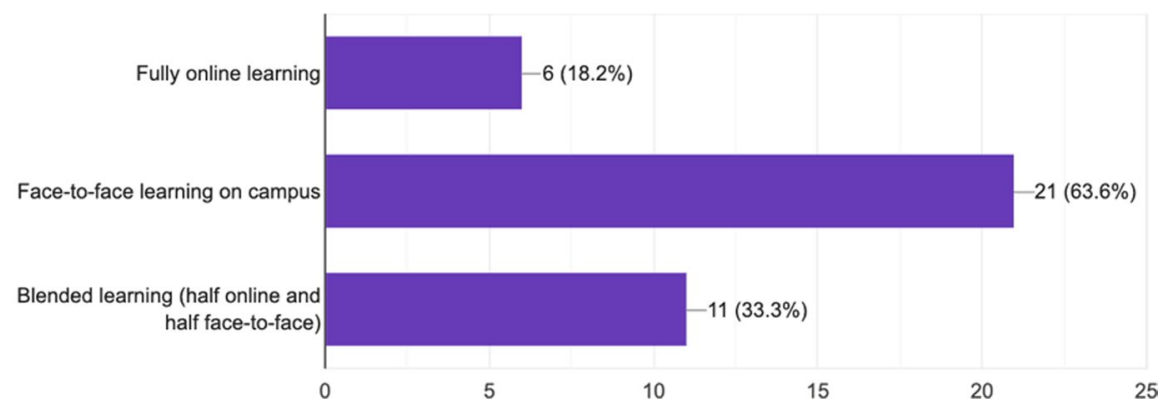

Fig. 2 Post COVID-19 Learning Preference

Another student opted for face-to-face learning as she found it hard to get enough support from the instructor online:

Understanding calculations and Math problems also became more challenging because my professors can no longer explain them to me one-on-one and I cannot always stop them during class and keep asking them questions because that is harder to do online.

Another student with a different learning difficulty preferred face-to-face instruction claiming that she is able to follow the lesson and understand better in class. The student said:

In a face-to-face class, instructor writes on the board, and I will be writing with him as well. That way, the information will stick into my mind. But, when using Zoom online or whatever platform they were using before, it was hard for me to write with them. So, I end up not writing anything in an online class. What is in my mind will stay in my mind with them in classroom.

Similarly, another student reported that she found it hard to take notes in online classes, that she was then left behind and relied on other students to explain to her what the instructor had taught. The student said:

Sometimes I do not understand the professors and I have to go and meet them again or ask my friends what he (professor) meant and what he wants us to do for the assessment. I cannot take notes in an online class, it is very hard for me.

Face-to-face learning was preferred by some students because they did not like virtual field experiences and they felt online learning did not allow them to interact extensively. Two participants reported on this issue saying:

Teaching needs more interaction between teacher and learners especially for early childhood. It is difficult to have these interactions online. I did Practicum III online, and I asked the mentor teacher how she interacts with children online. She 
said, that is the biggest problem. It is difficult to know a child's reaction online and interaction is limited which makes online learning hard (First participant).

I prefer $100 \%$ face-to-face. This is because in a face-to-face class, I listen to the professor directly and I get it. If it is online, sometimes I get confused. I take time to get it and there are many distractions. I cannot concentrate online like I do in a face-to-face class. I can understand when a professor is explaining and see when he is drawing in a face-to-face class (Second participant).

Another participant preferred face-to-face as she had a hard time understanding instruction online. The student said: "I had a hard time understanding some things because of online. I feel like I am distracted and not motivated to learn because we are at home." Another student opted for face-to-face learning on campus saying: "face-to-face is better and I am more comfortable and it is more convenient. I hope it will resume back on compus soon."

Students who opted for fully online learning post-COVID-19 preferred that mode mainly because of extraordinary convenience which was presented earlier in this section of results. Students also preferred an online learning mode as there was a significant improvement in their academic performance. The following exerpts support the statement:

I am so happy because it was hard when I started. It is not easy for subjects like Math and Chemistry which I am majoring in as they require vision. I managed to get good grades (3As and 2 A-). I did not get any Bs in my courses Allahamdulila (thank Allah).

My academic performance became better, much better as I got 2 straight As in one semester. I got good grades.

Allahamdulilla (thank God) my academic performance has increased. Before the pandemic, I do not know how my GPA was low, but now it has increased to 2.71 which is an improvement Allahamdulilla (thank Allah).

Eleven students (33.3\%) opted for a combination of online learning and face-to-face classes to form blended learning post-COVID-19. One participant said:

For me, I like both, but I am more comfortable online. I find myself performing better in online learning as I can participate a lot. I will not be shy to speak as I was in face-to-face classes. I prefer online but also, I like face-to-face.

Similarly, another student said: "I prefer blended learning as it allows me to do practical courses on campus and lectures online. In other words, I prefer blended learning for practical courses, and online learning for lectures." SEND students had different experiences and perspectives of online learning.

\section{Discussion}

SEND students who participated in this study revealed multiple perspectives about online learning. This challenges academics in institutions of higher learning to be more flexible and practice the fundamental principles of the universal design for 
learning in order to cater for the diverse needs of all students. It is not going to be easy to accommodate the needs of all SEND students as they have different preferences (Barden, 2017). However, students who do not have special needs or disabilities also have different preferences and this makes it possible for academics to find a way to accommodate all students (Sandoval et al., 2021). Reasonable accommodation is critical for SEND students whether they study online, face-to-face or through blended learning. Reasonable accommodations maximises SEND students' participation and promotes collaboration which is an intergral component of the Multimodal Model for Online Education.

Collaboration was evident in this study as SEND students interacted with other students in small tutorial groups. Fredericksen (2015) and Picciano (2017) state that collaborative learning is critical in the Multimodal Model for Online Education as it allow peers to co-create knowledge and engage in learning fully. SEND students in Spain were afforded some reasonable accommodations in accordance with their special needs and disabilities (Zabeli et al., 2021). Such support levelled the playing field and enabled SEND students to fully engage in the learning process. This refutes an argument that if differentiated support is afforded to SEND students, standards will be lowered or that this gives them preferential treatment (Cook et al., 2009). It is about levelling the playing field and offering equal opportunities to all students to make them engage with content and enhance their learning experiences (Zhang et al., 2010).

Through collaborations between SEND students and tutors, lecturers and SAS staff, the social or emotional element within the Multimodal Model for Online Education (Picciano, 2017) was formed. Social or emotional element emerged in this study through social interactions and engagements which SEND students had with the proximal settings. The interactions happened in different ways which challenged SEND students to use their cognitive skills to answer questions which were asked. Questionning technique is an integral element of the Multimodal Model for Online Education as it promotes students' critical thinking and analytical skills which help them to solve problems (Picciano, 2017). SEND students would not be able to learn optimally if their accommodations were not met.

The nature of support which the students were getting and which was revealed in this study is in line with definition of reasonable accommodation as given by the CRPD:

Necessary and appropriate modification and adjustments not imposing a disproportionate or undue burden, where needed in a particular case, to ensure to persons with disabilities the enjoyment or exercise on an equal basis with others of all human rights and fundamental freedoms (United Nations, 2006).

As part of reasonable accommodation, SEND students' assessments were modified in different ways. This reasonates with the evaluation or assessment element of the Multimodal Model for Online Education which Picciano (2017) conceptualises as the most crucial element of the model as it shows students' learning progress.

Post-COVID-19, whether teaching is done online, face-to-face or is blended, SEND students need to continuously get support otherwise they will not be able to maximise their learning potentials. When the global pandemic is over, it is expected 
that teaching and learning will not go back to the same way it was before (International Commission on the Futures of Education, 2020). Blended learning is likely to be the most dominant approach as it caters for the needs of students who prefer online learning and those who prefer face-to-face instruction. Chiroma et al. (2021) postulate that post-COVID-19, all pre-service teachers are going to need skills which enable them to work using both online and face-to-face modes. Both SEND students and lecturers will be expected to be able to optimise usage of LMS in order to enhance learning experiences. A LMS can be used for storing content, among other uses, and it is one of the elements of the Multimodal Model for Online Education (Picciano, 2017). The use of a LMS is likely to increase post-COVID-19 as many instructors learnt how to use it during the time when ERL started in 2020.

\section{Conclusion}

The purpose of this study was to examine SEND students' perspectives of ERL in the UAE. It is concluded that the learning modality most suitable for special needs students is determined by the nature of their disability and learning difficulty. For students who can not stay on a device for a long period, face-to-face learning will be preferrable. On the contrary, for some students with visual impairment, online learning is preferrable to most of them as they rely on their sense of hearing. It is therefore prudent for them to opt for online learning where they can get quality recordings and will be able to adjust room lighting and alter sitting positions to suit their condition. It is important to note that no generalisations can be made as some visually impaired students may prefer face-to-face or blended learning to online learning. The choice of either face-to-face instruction or online learning is dependent on a student's special needs and disability. It is a fallacy of composition to generalise that all SEND students like a similar mode of instruction. What is critical is to investigate the individual needs of every special needs student and afford him/her differentiated support to meet their diverse needs and consequently enhance their learning experiences. Multiple perspectives of online learning shared by SEND students in this study challenge institutions of higher learning to be more flexible in terms of modes of delivery that they use. There is a need for more blended learning and face-to-face classes in order to accommodate diverse needs of SEND students. This article adds contribution to the body of literature by widening the concept of differentiation of instruction in relation to the Multimodal Model for Online Education. This is done to cater for the diverse learning needs of SEND students in online learning.

\section{Appendix}

\section{Open ended questions}

1. I am getting enough support in online learning (Strongly disagree, Disagree, Neutral, Agree, Strongly agree) 
2. I was able to get help from the disability department at my university (Strongly disagree, Disagree, Neutral, Agree, Strongly agree)

3. My university offered adequate academic resources to assist me with online learning (Strongly disagree, Disagree, Neutral, Agree, Strongly agree)

4. My accommodations are being met in online learning? (Strongly disagree, Disagree, Neutral, Agree, Strongly agree)

5. My university has been supportive in facilitating the move to online learning, teaching and assessment during this time of Covid-19. (Strongly disagree, Disagree, Neutral, Agree, Strongly agree)

6. Which learning option would you prefer after COVID-19: (Fully online learning; Face-to-face learning on campus; Blended learning).

7. Rate the quality of support you received from your instructors online (Exceptional, Adequate, Fair, Poor)

\section{Interview questions}

1. What are your experiences of online learning during this time of Covid-19. (explain your answer fully)

2. What are the challenges that you are facing with online learning? Explain fully.

3. What kind of support are you getting to enhance your online learning experiences? Is it enough? Explain fully

4. What additional support would you like to get in order to make your online learning experiences better?

5. Explain the learning model you prefer post COVID-19. Justify your answer fully

\section{Declarations}

Authors declare that this is their original work. It is neither published anywhere nor considered for publication by another journal. The research adhered to ethical guidelines and there is no conflict of interest.

\section{References}

Ahead (2020). Learning from Home During Covid-19: A Survey of Irish FET and HE Students with Disabilities. AHEAD Educational Press. Retrieved September 15, 2021, from https://ahead.ie/userfiles/ files/shop/free/Learning\%20from $\% 20$ Home $\% 20$ During $\% 20$ Covid-19\%20-\%20A $\% 20$ Survey $\% 20$ of $\%$ 20Irish\%20FET\%20and\%20HE\%20Students\%20with\%20Disabilities.pdf

Alhammadi, M. M. (2017). Challenges facing students with vision impairment at UAE higher educational institutions. The Emirates Center for Strategic Studies and Research.

Ali, L. (2021). Accessible websites for everyone - A case of UAE universities websites. International Journal of Information and Education Technology, 11(4), 164-170.

Barden, J. (2017). 5 Benefits Of eLearning For Disabled Students. eLearning Industry. Retrieved September 14, 2021, from https://elearningindustry.com/5-benefits-of-elearning-for-disabled-students

Benkohila, A., Elhoweris, H., \& Efthymiou, E. (2020). Faculty attitudes and knowledge regarding inclusion and accommodations of special educational needs and disabilities students: a United Arab Emirates case study. Psycho-Educational Research Reviews, 9(2),100-111. Retrieved September 15, 2021, from https://www.journals.lapub.co.uk/index.php/PERR 
Bergman, D. (2020). Pre-service teachers' perceptions of ethical student evaluation practices: Comparing impact of online and face-to-face coursework. Journal of Technology and Teacher Education, 28(4), $665-689$.

Chiroma, J. A., Meda, L., \& Waghid, Z. (2021). Examining emergency remote teaching using the Community of Inquiry Framework: Lecturer experiences in a Kenyan University. International Journal of Information and Communication Technology Education, 17(4), 1-16. https://doi.org/10.4018/ IJICTE.20211001.oa17

Cohen, L., Manion, L., \& Morrison, K. (2017). Research methods in education (7th ed.). Routledge.

Cook, L., Rumrill, P., \& Kersley, M. T. (2009). Priorities and understanding of faculty members regarding college. International Journal of Teaching and Learning in Higher Education, 21(1), 84-96.

Creswell, J. W. (2012). Educational research: Planning, conducting and evaluating quantitative and qualitative research. Pearson.

Creswell, J. W., \& Poth, C. N. (2018). Qualitative inquiry and research design: Choosing among five approaches. Sage.

De Asis, R. (2016). Reasonableness in the concept of reasonable accommodation. The Age of Human Rights Journal, 6(June 2016), 42-59. https://doi.org/10.17561/tahrj.v0i6.2928

Dikusar, A. (2018). The use of technology in special education. ELearning industry. Retrieved September 15, 2021, from https://elearningindustry.com/use-of-technology-in-special-education

Fredericksen, E. (2015). Is online education good or bad? And is this really the right question? The Conversation. Retrieved September 15, 2021, from: https://theconversation.com/is-onlineeducationgood-or-bad-and-is-this-really-the-right-question-35949

Garrison, D. R., Anderson, T., \& Archer, W. (2000). Critical inquiry in a text-based environment: Computer conferencing in higher education. Internet and Higher Education, 2(2-3), 87-105.

Jelinska, M., \& Paradowski, M. B. (2021). Teachers' perception of students coping with emergency remote instruction during the COVID-19 pandemic: The relative impact of educator demographics and professional adaptation and adjustment. Frontiers in Psychology, 12, 648443. https://doi.org/10. 3389/fpsyg.2021.648443

Jia, L., \& Santi, M. (2021). Inclusive education for students with disabilities in the global COVID-19 outbreak emergency: Some facts and thoughts from China. Disability \& Society, 36(7), 1186-1191. https://doi.org/10.1080/09687599.2021.1925226

Kim, J. (2020). Learning and teaching online during Covid-19: Experiences of student teachers in an early childhood education practicum. International Journal of Early Childhood, 52(2), 145-158. https://doi.org/10.1007/s13158-020-00272-6

Lapan, D. S., Quartaroli, T. M., \& Riemer, J. F. (2012). Introduction to qualitative research. In S. D. Lapan, T. M. Quartaroli, \& J. Riemer (Eds.), Qualitative research: An introduction to methods and designs (pp. 3-18). Josey-Bass.

Lopez-Gavira, R., Orozco, I., \& Dome'nech, A. (2021). Is pedagogical training an essential requirement for inclusive education? The case of faculty members in the area of social and legal sciences in Spain. PLoS One, 16(7), 1-20. https://doi.org/10.1371/journal.pone.0254250

Picciano, A. G. (2017). Theories and frameworks for online education: Seeking an integrated model. Online Learning, 21(3), 166-190.

Sandoval, M., Morgado, B., \& Doménech, A. (2021). University students with disabilities in Spain: Faculty beliefs, practices and support in providing reasonable adjustments. Disability \& Society, 36(5), 730-749. https://doi.org/10.1080/09687599.2020.1751078

Schreuer, N., \& Sachs, D. (2014). Efficacy of accommodations for students with disabilities in higher education. Journal of Vocational Rehabilitation, 40(1), 27-40.

Sim, S., Sim, H., \& Quah, C. (2021). Online learning: A post Covid-19 alternative pedagogy for University students. Asian Journal of University Education, 16(4), 137-151. https://doi.org/10.24191/ajue. v16i4.11963

United Nations (2006). United Nations Convention on the Rights of Persons with Disabilities. Retrieved July 15, 2020, from https://www.un.org/development/desa/disabilities/convention-on-the-rights-ofpersons-with-disabilities.html

Vasek, D. (2005). Assessing the Knowledge Base of Faculty at a Private Four Years Institution. College Student Journal, 26(2), 307-315.

Waghid, Z., Meda, L., \& Chiroma, J. (2021). Assessing cognitive, social and teaching presences during emergency remote teaching at a south African University. International Journal of Information and Learning Technology. https://doi.org/10.1108/IJILT-01-2021-0006

Yin, R. K. (2018). Case study research and applications: Designs and methods. Sage. 
Zabeli, N., Kaçaniku, F., \& Koliqi, D. (2021). Towards the inclusion of students with special needs in higher education: Challenges and prospects in Kosovo. Cogent Education, 8(1), 1-20. https://doi. org/10.1080/2331186X.2020.1859438

Zhang, D., Landmark, L. J., Reber, A., Hsu, H.-Y., Kwok, O., \& Benz, M. (2010). University faculty knowledge, beliefs, and practices in providing reasonable accommodations to students with disabilities. Remedial and Special Education, 31(4), 276-286.

Publisher's note Springer Nature remains neutral with regard to jurisdictional claims in published maps and institutional affiliations. 